\title{
THE FEMALE CARRIER OF HAEMOPHILIA - A PROBLEM FOR THE ANAESTHETIST
}

\author{
Martin J. Inwood and David B. Meltzer
}

IT IS NOW RECOGNIZED that females who are obligatory carriers for haemophilia can often have quite variable levels of either Factor $V I I I$ or Factor $I X{ }^{\prime}$ This variability is due to the process of lyonization in sex chromatin formation, where $\mathrm{X}$ chromosomes possessing the defective Factor $V I I I$ or Factor $I X$ gene are inactivated along with other normal $X$ chromosomes containing full factor activity. As a result of this random process of inactivation, it is possible for a female to present with a spectrum of factor deficiency ranging from a level low enough to be consistent with a diagnosis of severe haemophilia (the random process has inactivated more normal rather than abnormal X chromosomes) to levels high enough to be indistinguishable from normal individuals (more abnormal compared to normal $X$ chromosomes have been inactivated). The former group have a clinical presentation very similar to that of severe haemophilia and can be incorrectly designated as female haemophiliacs rather than haemophilia carriers. Conversely, at the other end of the spectrum, the carrier female has a clinical presentation consistent with that of a haemostatically normal person and a factor level which prevents the diagnosis of haemophilia carrier being made. Identification of such individuals must be made on the basis of family history and, for the purposes of this paper, an obligatory carrier is defined as a female who has either two sons with the same defect; ove son and one other male within the maternal family with the same defect, or is the daughter of a known haemophiliac. ${ }^{2}$

It is not surprising, therefore, that carrier females, who have low levels of either Factor $V I I I$ or $I X$, can often present with exactly the same complications as their male counterparts. ${ }^{3,4}$ Such presentations can be confusing, obscure or unexpected, and the following case histories reflect rare but very real diagnostic and management problems for the attending surgeon and anaesthetist.

\section{Case History I}

This was a 22-year-old married woman with

Martin J. Inwood, M.D., F.R.C.P.(C), David B. Meltzer, M.D., F.R.C.P.(C), Division of Haematology, St. Joseph's Hospital, London, Ontario. one haemophiliac son and one nephew, both having Factor VIII deficiency. Her past history included increased susceptibility to bruising, with occasional small subcutaneous haematomata. She had been treated intermittently for menorrhagia and subsequent iron deficiency anaemia since early adulthood. Her three normal deliveries had been accompanied by postpartum haemorrhages, and it had been necessary to administer blood transfusions on two of these occasions. A tonsillectomy at the age of 12 and two separate tooth extractions also required transfusion of fresh blood because of severe postoperative haemorrhage. She was referred for assessment before an anticipated tooth extraction. Consistent with her presenting history, her PTT was elevated to 46 seconds with a Factor VIII level of 15 per cent. All other tests of haemostatic function, including ristocetin aggregation and platelet function tests were normal.

Before the tooth extraction she was given ten units of cryoprecipitate and this elevated her factor level to 55 per cent. The tooth was extracted and the post-operative care included the use of epsilon aminocaproic acid (Amicar) 2 grams per os q $4 \mathrm{~h}$ for a total of 48 hours, along with further infusions of cryoprecipitate. No bleeding occurred and the post-operative course was uneventful.

\section{Case History 2}

This was a 34-year-old married woman with one haemophiliac son and three nephews, all with Factor VIII deficiency. She had a presenting history of easy bruising of the extremities. She had no previous operations and her one obstetrical delivery had been uneventful. She had had several teeth extracted without complications. Her menstrual periods had been considered "heavy", but normal. A subtotal hysterectomy was done for carcinoma in situ and five days postoperatively vaginal bleeding started which initially was thought to be related to a small focus of local infection. Subsequently the haemorrhage became severe enough to require transfusion with whole blood and local surgical exploration. No active bleeding site was identified, although generalized oozing from the operative site was 
noted. After massive blood replacement another exploration was required, resulting in ligation of an internal iliac artery, which finally controlled the bleeding. During this time she received medications containing aspirin.

Three months after the first procedure she was referred for investigation of a left lower quadrant abdominal mass. Laboratory testing at that time showed a Factor VIII level of 30 per cent with no evidence of other haemostatic abnormalities. As surgical exploration was considered necessary, she was prepared with 10 units of cryoprecipitate which raised her Factor $V I I I$ level to 70 per cent. Cryoprecipitate transfusions were continued at 12-hour intervals during and after the exploratory laparotomy which revealed a haemorrhagic cyst of the left ovary. Her subsequent course was uneventful, and cryoprecipitate was discontinued after six days. There were no complications.

\section{Case History 3}

This patient was a 54-year-old female, mother of two haemophiliac sons and having one grandson, all with Factor VIII deficiency. She was admitted complaining of acute onset of left lower quadrant flank pain. Her previous history included easy bruising of the extremities, mild haemorrhage after tooth extractions and a hysterectomy and appendectomy for which she required blood transfusions. She had had two postpartum haemorrhages requiring transfusion. On examination she had marked tenderness and guarding of the left flank and lower abdomen. Rectal examination was normal. The remainder of the physical examination was non-contributory. Laboratory results indicated a leucocytosis of 11,400 per $\mu l$ with neutrophilia and a shift to the left. The haemogtobin level was initially $12.4 \mathrm{gm}$ per cent and decreased over the next 24 hours to $8.2 \mathrm{gm}$ per cent. Biochemical studies were normal, including urinalysis and stool for occult blood. Her Factor $I X$ level was 24 per cent. Radiological examination of the abdomen and genito-urinary system were normal. Initially it was suspected that the patient had either an ovarian haemorrhage, an intra-abdominal malignancy, or a retroperitoneal haemorrhage. Immediate replacement with packed red cells and fresh frozen plasma increased her haemoglobin to $11.2 \mathrm{gm}$ per cent and the Factor $I X$ level was raised to 38 per cent. No medication containing ASA was given.

Her clinical condition and haemoglobin remained stable and over the next five days her symptoms gradually resolved. Seven days after admission a well-defined area of tenderness was noted on the left lateral margin of the abdominal wall, accompanied by slight bruising of the left flank. Tensing of the abdominal muscles, passing of stool and tension on the abdominal wall produced marked discomfort. These symptoms rapidly resolved and she was discharged with a diagnosis of abdominal wall haematoma and retroperitoneal haemorrhage. Subsequent followup was uneventful, with complete resolution of abdominal symptoms.

\section{Discussion}

The preceding cases illustrate some of the difficulties which can be experienced by women who are obligatory carriers for haemophilia. They represent three different ways in which such a patient can present.

The first carrier had a definite history for a haemostatic defect and the Factor VIII level of 12 per cent substantiated that she had a clinical history compatible with that of a mildly affected haemophiliac. The surgeon had correctly identified the importance of this history and this enabled adequate preparation of the patient for a subsequently uneventful tooth extraction. Her management was no different to that normally used for any mild haemophiliac undergoing this type of procedure, and this includes the use of aminocaproic acid in conjunction with Factor $V I I I$ replacement for oral mucosal procedures.

The second patient, with a relatively insignificant presenting history, had a partial hysterectomy without immediate problems. However, when relatively benign post-operative complications occurred, these were accompanied by catastrophic haemorrhage requiring two further surgical explorations and multiple blood transfusions. Although her $\mathbf{3 0}$ per cent factor level was adequate for the initial operation it was not sufficient to maintain adequate haemostasis in the presence of complications. The use of adequate pre-operative and post-operative Factor VIII replacement allowed for another abdominal intervention in a previously operated area with no post-operative bleeding complications.

The third patient presents as an acute abdomen with signs compatible with that of an intraabdominal haemorrhage. Her stable clinical course allowed for replacement therapy and careful observation which confirmed the presence of the haemorrhage. This not-uncommon spontaneous haemorrhage seen in mild haemophiliacs 
can cause considerable problems as it closely mimics other abdominal pathology. Transfusion is often required, as large amounts of blood can be sequestered into the muscle mass with dissection into retroperitoneal tissues.

In light of the complications which these cases illustrate, it is suggested that if a female patient presents with a previous family history of haemophilia, the following protocol be used if an operation is contemplated.

1. A thorough family history is to be taken to decide whether or not the woman is an obligatory or possible carrier. If the factor deficiency has not already been substantiated in other members of the family, it is most important that they also be tested along with the woman, in order to confirm the specific factor deficiency, e.g. either Factor $V I I I$ or Factor $I X$.

2. A full haemostatic investigation to be undertaken to obtain a basal level of the affected factor and to exclude other conditions which could be confused with haemophilia, such as Von Willebrand's disease.

3. If the level of the factor is below 60 per cent, all platelet active drugs, including ASA, must be avoided. Acetominophen and codeine are suitable oral alternatives. If an operation is done, the level of factor must be regularly assessed during the first seven post-operative days and, if the factor level falls below 40 per cent, replacement with Factor $V I I I$ or Factor $I X$ concentrates must be considered. The amounts given should be sufficient to raise the level of deficient factor to above 50 per cent for any given time period.

4. If the factor level is below 40 per cent, adequate pre-operative replacement of the deficient factor must be given, and the level maintained at a very minimum of 50 per cent for at least seven days post-operatively. Again, platelet active drugs must be avoided. If an operation on the oral mucosa is necessary, such as tooth extraction, epsilon aminocaproic acid can be used to advantage. ${ }^{5}$

There is presently some debate as to the appropriate concentrate that should be used for replacement therapy. In most instances, the use of cryoprecipitate is perfectly acceptable for Factor VIII deficient individuals and, if satisfactory levels cannot be maintained with this material, the use of lyophilized commercial concentrates is quite acceptable, even though in the individual who has not been previously transfused a higher incidence of post-transfusion hepatitis could be expected. ${ }^{6}$ In the third case it was noted that the Factor $I X$ level was not raised by more than 10 per cent each day after infusion of approximately $750 \mathrm{ml}$ of fresh frozen plasma. If indeed adequate levels cannot be maintained, Factor $I X$ lyophilized concentrates can be used, but again with the increased chance of hepatitis in individuals not previously transfused. It is also important to note that, if Factor $I X$ concentrates are used, the individual must have no evidence of hepatic insuffciency in order to avoid possible thromboembolic complications. ${ }^{6}$

The use of nonsteroidal anti-inflammatory drugs must be avoided in these people, particularly during operative procedures. The second patient had received acetylsalicylic acid during her first operative intervention and this could well have contributed to the severity of the postoperative haemorrhage.

The anaesthetist plays a central role in the management of such patients, because the attending physician and surgeon are not always aware of the significance of a suboptimal Factor VIII or Factor $I X$ level. Pre-operative assessment by the anaesthetist will not only identify such a potentia] risk but, using a relatively straightforward diagnostic and therapeutic plan, will achieve maximum safety for the patient during the crucial operative and post-operative intervals.

\section{SUMMARY}

Three case histories reflect the difficulties of pre-operative assessment and management of female obligatory carriers for Factor VIII or Factor $I X$ deficiency (haemophilia).

The dangers of operation in these individuals is emphasized in view of the often confusing laboratory and clinical findings in this group of patients. A protocol is presented which, if used by the anaesthetist, will provide for logical and safe diagnostic and therapeutic approaches for these patients.

\section{RÉSUMÉ}

La chirurgie des femmes porteuses de déficiences en facteurs $V I I I$ et $I X$ (hémophilie) peut s'accompagner de problèmes graves lors de la chirurgie elle-même ou dans les suites postopératoires. Trois cas cliniques illustrent le fait que l'identification de ces patientes peut ètre difficile à moins que l'on ne les rechereche activement avant l'intervention. Les auteurs proposent un protocole permettant d'en arriver à un diagnostic logique et d'établir une ligne de conduite appropriée. 


\section{ACKNOWLEDGEMENTS}

Drs. D. MacKenzie, E. Heath and P. Harding, St. Joseph's Hospital, London, Ontario, kindly gave permission for their patients' histories to be presented.

\section{REFERENCES}

I. Ratnoff, O.D. \& Jones. P.K. The laboratory diagnosis of the carrier state in classic hemophilia. Ann. Int. Med. 86: 521 (1977).

2. Ratnoff, O.D. \& Jones, P.K. The detection of carriers of classic hemophilia. Am. J. Clin. Path. 65: 129 (1976).

3. Eyster, M.E., Ladda, R.L.. \& Bowman, H.S.
Carriers with excessively low factor VIII pjocoagulant activity (VIII AHF): a study of two unrelated families with mild hemophilia A. Blood 49: 607-618(1977).

4. Kitchens, C.S., Levin, J., \& King Smith W. Hemorrhagic diathesis in a carrier of hemophilia $B$. Am. J. Med. 60: 138-143 (1976).

5. WALSH, P.N. \& RizZA, C.R. Epsilon-aminocaiproic acid therapy for dental extractions in haemophilia and Christmas disease: a double blind controlled trial. Brit. J. Haemat. 20: 463-475 (1971).

6. WhITE, G.C., ROBERTS, H.R., KINGDON, H.S., \& LUNDBLAD, R.L. Prothrombin complex concentrates: potentially thrombogenic materials and clues to the mechanism in rivo. Blood 49: 159-170 (1977). 